\title{
Species-specific viability analysis of Pseudomonas aeruginosa, Burkholderia cepacia and Staphylococcus aureus in mixed culture by flow cytometry
}

Marc Rüger $^{1 *}$, Mandy Ackermann ${ }^{1}$ and Udo Reichl ${ }^{1,2}$

\begin{abstract}
Background: Bacterial species coexist commonly in mixed communities, for instance those occurring in microbial infections of humans. Interspecies effects contribute to alterations in composition of communities with respect to species and thus, to the course and severity of infection. Therefore, knowledge concerning growth and viability of single species in medically-relevant mixed communities is of high interest to resolve complexity of interspecies dynamics and to support development of treatment strategies. In this study, a flow cytometric method was established to assess the species-specific viability in defined three-species mixed cultures. The method enables the characterization of viability of Pseudomonas aeruginosa, Burkholderia cepacia and Staphylococcus aureus, which are relevant to lung infections of Cystic Fibrosis (CF) patients. The method combines fluorescence detection by antibody and lectin labeling with viability fluorescence staining using SYBR ${ }^{\oplus}$ Green I and propidium iodide. In addition, species-specific cell enumeration analysis using quantitative terminal restriction fragment length polymorphisms (qT-RFLP) was used to monitor the growth dynamics. Finally, to investigate the impact of substrate availability on growth and viability, concentrations of main substrates and metabolites released were determined.

Results: For each species, the time course of growth and viability during mixed culture cultivations was obtained by using QT-RFLP analysis in combination with flow cytometry. Comparison between mixed and pure cultures revealed for every species differences in growth properties, e.g. enhanced growth of $P$. aeruginosa in mixed culture. Differences were also observed for B. cepacia and S. aureus in the time course of viability, e.g. an early and drastic reduction of viability of $S$. aureus in mixed culture. Overall, $P$. aeruginosa clearly dominated the mixed culture with regard to obtained cell concentrations.
\end{abstract}

Conclusions: In combination with qT-RFLP analysis, the methods enabled monitoring of species-specific cell concentrations and viability during co-cultivation of theses strains. Experimental findings suggest that the predominance of $P$. aeruginosa over B. cepacia and $S$. aureus in mixed culture under the chosen cultivation conditions is promoted by more efficient substrate consumption of $P$. aeruginosa, and antagonistic interspecies effects induced by P. aeruginosa.

Keywords: Viability analysis, Mixed communities, Flow cytometry, T-RFLP, Cystic fibrosis, Pseudomonas aeruginosa, Burkholderia cepacia, Staphylococcus aureus, Interspecies effects

\footnotetext{
* Correspondence: rueger@mpi-magdeburg.mpg.de

${ }^{1}$ Chair of Bioprocess Engineering, Otto von Guericke University, Magdeburg,

Germany

Full list of author information is available at the end of the article
} 


\section{Background}

Microbial infections in humans are often characterized by a highly complex community of multiple bacterial species. Interspecies effects contribute to alterations in the composition of communities with respect to species and thus, to the course and severity of microbial infections. Moreover, changes in the composition of communities and interspecies effects may affect efficacy of antibiotics with severe consequences on therapeutic success. Consequently, determination of the dynamics of individual species in mixed communities is of high interest. Therefore, not only absolute and specific cell enumeration is required, but also information regarding viability of species. The composition of bacterial mixed communities can be determined efficiently by terminal restriction fragment length polymorphisms (T-RFLP) analysis. This has been widely demonstrated in numerous studies [1-6]. However, only few reports present absolute and species-specific cell numbers. For quantitative characterization of mixed communities by T-RFLP, Trotha et al. introduced an internal quantification standard [7], an 16S ribosomal RNA (rRNA) gene fragment from a known species with a defined cell number. Schmidt et al. adapted this quantitative T-RFLP (qT-RFLP) method for species-specific cell enumeration of a three-species mixed model community, comprising $P$. aeruginosa, $B$. cepacia and $S$. aureus, relevant to infections of lung of Cystic Fibrosis (CF) patients [8]. Furthermore, the authors characterized the growth of these species in a defined mixed culture in chemostat cultivations, and a mathematical chemostat model was established to identify interspecies effects [9]. Finally, Riedele et al. used the qT-RFLP protocol to study the efficacy of the antibiotic ceftazidime on the growth of these species in mixed culture [10]. While qT-RFLP method allows to discriminate between species and to quantify cell concentration, viability is not determined. The latter, however, is of crucial importance for assessing antibiotic efficacy in case cell damage does not result in cell lysis but in loss of cellular functions, e.g. membrane integrity. Only based on the combination of qT-RFLP and speciesspecific viability analysis the detailed description of growth dynamics and the thorough characterization of interspecies effects are feasible.

T-RFLP can also be used for selective detection of the viable cell fraction, when the method is modified as recently reported by Rogers et al., who stained cells with propidium monoazide (PMA) prior to cell disruption [11]. This dye, which intercalates with DNA, is generally excluded from viable cells with intact membranes [12]. By photo activation, PMA binding leads to irreversible modification of DNA, thus preventing DNA of dead cells with an permeabilized membrane from amplification by PCR [11]. While the combination of standard T-RFLP with PMA-T-RFLP allows for discrimination between viable and dead cells, it has the disadvantage that it does not allow for identification of cells with a slightly damaged membrane, which may occur during growth due to short-term perforation of the cell wall during cell division and cell wall synthesis [13]. Moreover, the PCR-based quantification of viable cells using PMA staining can be affected by the presence of a high number of dead cells in the sample [14]. Due to these drawbacks a flow cytometric method for characterization of species-specific viability had been established. Flow cytometry provides a powerful tool for viability analysis of bacteria by applying fluorescent probes, which target or indicate specific cell functions such as respiratory activity, enzyme activity, substrate uptake, efflux pump activity, membrane potential or membrane integrity [15]. Additionally, species discrimination can be achieved by species-specific fluorescence labeling of cells, e.g. by immunofluorescence using monoclonal antibodies. Flow cytometry has been widely applied for viability determination of bacteria, mainly by assessing membrane integrity of cells (see review [13]). Often, a nucleic acid double-staining (NADS) method is used using propidium iodide (PI) for identification of dead cells, and $\mathrm{SYBR}^{\circ} \mathrm{Green}$ I for total cell staining [16]. This approach has been demonstrated successfully for a wide range of different species [17-23]. PI is generally excluded from cells with intact membranes, whereas it enters cells with permeabilized membranes, staining them by binding DNA as well as RNA [24]. Concomitantly, SYBRGreen I penetrates all cells and intercalates selectively with double-stranded DNA [25]. Therefore, fluorescence detection enables discrimination between viable and dead cells exhibiting an intact or permeabilized membrane, respectively. In contrast to PMA-T-RFLP, detection of cells with a slightly damaged membrane can be obtained after optimization of staining conditions, as recently demonstrated for S. aureus [26]. For determination of species-specific viability by flow cytometry, fluorescence species-specific detection is a key prerequisite. Bacterial species can be detected specifically by fluorescence labeling with antibodies or lectins that bind specifically to epitopes or molecules on cell surface, and by labeling with nucleotide probes that hybridize specifically to complementary strands of $16 \mathrm{~S}$ rRNA. Latter technique is not recommended for use in combination with viability staining, since labeling requires permeabilization of membranes. Even though fluorescence labeling using specific antibodies (immunofluorescence labeling) and lectins has been widely established in flow cytometry, the combination with viability staining has been used only very rarely to determine the species-specific viability in mixed cultures (see review [27]).

In this study, a flow cytometric method is presented for assessment of the species-specific viability in defined threespecies bacterial mixed cultures comprising $P$. aeruginosa, 
B. cepacia and S. aureus, relevant to infections of the lung of CF patients. The approach combines species-specific fluorescence detection by lectin and antibody labeling with viability fluorescence staining using SYBR Green I and PI. Additionally, for growth characterization in mixed culture, species-specific cell enumeration analysis using qT-RFLP was applied. Finally, to study the effect of substrate availability on growth and viability, concentrations of main substrates and metabolites released into culture medium were quantified using an enzymatic assay and high performance liquid chromatography (HPLC) analysis.

\section{Methods}

\section{Bacterial strains}

Pseudomonas aeruginosa PAO1 was supplied by Kathrin Riedel (Department of Microbiology, Technical University Munich, Germany). Burkholderia cepacia DSM 7288 was supplied by the German Collection of Microorganisms and Cell Cultures (DSMZ, Braunschweig, Germany). Staphylococcus aureus ATCC 29213 was supplied by Brigitte König (Department of Medical Microbiology, Otto von Guericke University, Magdeburg, Germany).

\section{Culture medium}

For cultivation of bacteria, $\mathrm{Gibco}^{\bullet}$ cell culture basal medium powder M199 (without $\mathrm{NaCO}_{3}$ ) (Life Technologies, Carlsbad, CA, USA) buffered with phosphate was used. Additionally, nitrilotriacetic acid (NTA) was added to prevent precipitation. Briefly, $800 \mathrm{~mL}$ of ultrapure water, $16 \mathrm{~mL}$ of $0.25 \mathrm{mM}$ NTA solution (Sigma-Aldrich, Steinheim, Germany) in $0.6 \mathrm{M} \mathrm{NaOH}$ and $25 \mathrm{~mL}$ of sodium potassium phosphate buffer $\left(1.5 \mathrm{M} \mathrm{NaH}_{2} \mathrm{PO}_{4} /\right.$ $\mathrm{K}_{2} \mathrm{HPO}_{4}$, pH 7.0, Carl Roth, Karlsruhe, Germany) were mixed with the amount of powder indicated by the supplier and filled up to $1 \mathrm{~L}$ with ultrapure water [8].

\section{Cultivation conditions}

Bacteria were grown in $250 \mathrm{~mL}$ wide-neck Erlenmeyer flasks incubated in a humidified orbital shake incubator (Kuehner, Birsfelden, Switzerland) at $37^{\circ} \mathrm{C}$, rotation speed $200 \mathrm{rpm}$, eccentric radius $1.25 \mathrm{~cm}$, and relative humidity of $85 \%$. Cultivations of mixed and pure cultures were conducted. Inocula were prepared as described previously by Riedele and Reichl [10] from pure culture of each species. Briefly, cells were grown overnight in $20 \mathrm{~mL}$ of culture medium, subsequently harvested, centrifuged at 3,522 $\times \mathrm{g}$ for $10 \mathrm{~min}$ at $4^{\circ} \mathrm{C}$ (Heraeus ${ }^{\oplus}$ Multifuge $1 \mathrm{~S}-\mathrm{R}$, Thermo Scientific, Waltham, WA, USA), and washed with PBS (8 g/L $\mathrm{NaCl}, 0.2 \mathrm{~g} / \mathrm{L} \mathrm{KCl}, 1.15 \mathrm{~g} / \mathrm{L} \mathrm{NaH}_{2} \mathrm{PO}_{4}, 0.2 \mathrm{~g} / \mathrm{L} \mathrm{K} \mathrm{K}_{2} \mathrm{HPO}_{4}$, $\mathrm{pH}$ 7.4, Carl Roth, Karlsruhe, Germany). Afterwards, suspensions were centrifuged again $\left(3,522 \times \mathrm{g}, 10 \mathrm{~min}, 4^{\circ} \mathrm{C}\right)$, resuspended in $20 \mathrm{~mL}$ of fresh culture medium and cultivated for $1.5 \mathrm{~h}$. These cells were inoculated in $50 \mathrm{~mL}$ fresh pre-warmed culture medium. For both mixed and pure cultures, the inoculation volume of each species was adjusted to a total starting cell concentration of $1 \times 10^{6}$ cells $/ \mathrm{mL}$. Therefore, optical density at $650 \mathrm{~nm}$ $\left(\mathrm{OD}_{650}\right)$ (photometer Ultraspec 3000, Amersham Biosciences, Otelfingen, Switzerland) was adjusted for each species based on linear correlation between $\mathrm{OD}_{650}$ and cell concentration determined by flow cytometric absolute counting. Consequently, for mixed culture, the inoculation volume of each species was three times lower than for pure culture (ratio between starting cell concentrations of species corresponds to $1: 1: 1)$. Cells were then cultivated over a period of $32 \mathrm{~h}$.

For testing staining conditions, species were cultivated in pure cultures. Cells were grown overnight in $20 \mathrm{~mL}$ of culture medium, washed and regrown in $20 \mathrm{~mL}$ of fresh culture medium as described before. In contrast to inocula preparation, cells were cultivated over a period of $5 \mathrm{~h}$. From these cultures samples were taken after $2 \mathrm{~h}$ and $5 \mathrm{~h}$ (exponential and stationary phase) for testing staining.

All cultivations were conducted in three biological replicates.

\section{Sample preparation before staining}

Cells were harvested by centrifugation at 4,700 $\times \mathrm{g}$ for $10 \mathrm{~min}$ at $4^{\circ} \mathrm{C}$ (Heraeus ${ }^{\ominus}$ Fresco, Thermo Scientific, Waltham, WA, USA) and subsequently resuspended in Ringer solution $(39 \mathrm{mM} \mathrm{NaCl}, 1.4 \mathrm{mM} \mathrm{KCl}, 0.6 \mathrm{mM}$ $\mathrm{NaHCO}_{3}, 0.5 \mathrm{mM} \mathrm{CaCl}{ }_{2} \cdot 2 \mathrm{H}_{2} \mathrm{O}, \mathrm{pH}$ 7.2, Carl Roth, Karlsruhe, Germany). For fluorescence staining, Ringer solution was supplemented with $0.05 \mathrm{mg} / \mathrm{mL}$ glutaraldehyde (GTA) (50\% grade I, Sigma-Aldrich, Steinheim, Germany), $0.05 \%(\mathrm{~m} / \mathrm{v})$ BSA (Carl Roth, Karlsruhe, Germany), and $3 \mathrm{M} \mathrm{KCl} \mathrm{(Carl} \mathrm{Roth,} \mathrm{Karlsruhe,} \mathrm{Germany)} \mathrm{(pH} \mathrm{7.2).} \mathrm{For}$ analysis, samples were diluted with Ringer solution prior to staining if necessary to $\mathrm{OD}_{650}$ in a range of 0.01 to 0.04 to ensure total cell concentrations between $1 \times 10^{6}$ and $1 \times 10^{7}$ cells $/ \mathrm{mL}$.

To verify viability staining of dead cells, controls for membrane permeabilization (positive controls) were prepared for each species from pure cultures. Briefly, after resuspension in Ringer solution, samples were treated with 70\% (v/v) isopropanol (Merck, Darmstadt, Germany) for $1 \mathrm{~h}$ at room temperature (RT). Subsequently, suspensions were centrifuged at $4,700 \times \mathrm{g}$ for $10 \mathrm{~min}$ at $4{ }^{\circ} \mathrm{C}$ (see above) and washed. Then, cells were resuspended in Ringer solution and diluted to an $\mathrm{OD}_{650}$ in the range of $0.01-0.04$.

\section{Labeling of WGA with Mix-n-Stain ${ }^{\mathrm{TM}} \mathrm{CF}^{\mathrm{TM}} 405 \mathrm{~S}$}

For Gram-staining of $S$. aureus, working solutions of $0.18 \mathrm{mg} / \mathrm{mL} \mathrm{CF}^{\mathrm{m}} 405 \mathrm{~S}$ conjugated wheat germ agglutinin (WGA) were prepared. Briefly, $75 \mu \mathrm{g}$ of WGA 
(Vector Laboratories, Burlingame, CA, USA), diluted in ultrapure water with $0.1 \mathrm{M} \mathrm{NaHCO}$ (Carl Roth, Karlsruhe, Germany), were labeled with Mix-n-Stain ${ }^{\text {ms }}$ $\mathrm{CF}^{\mathrm{rm}} 405 \mathrm{~S}$ antibody labeling kit (Biotium Inc., Hayward, CA, USA) according to the protocol recommended by the manufacturer.

Antibodies for immunofluorescence detection of $B$. cepacia For indirect immunofluorescence labeling of $B$. cepacia, primary monoclonal antibodies $\left(1^{\circ} \mathrm{Ab}\right.$, mouse antiPseudomonas cepacia, IgG3, clone 1144/209, Biotrend Chemikalien GmbH, Köln, Germany) and R-phycoerythrin (R-PE) conjugated secondary monoclonal antibodies $\left(2^{\circ} \mathrm{Ab}\right.$, goat anti-mouse, IgG, Life Technologies, Carlsbad, CA, USA) were applied. For every day of experiment, fresh working solutions of $10 \mu \mathrm{g} / \mathrm{mL} 1^{\circ} \mathrm{Ab}$ and $60 \mu \mathrm{g} / \mathrm{mL} 2^{\circ} \mathrm{Ab}$ were prepared in Ringer solution.

\section{SYBR Green I and PI for viability staining}

For staining, working solutions of 1:100 SYBR ${ }^{\circ}$ Green I $(10,000 \times$ concentrate in DMSO, Life Technologies, Carlsbad, CA, USA) and $1 \mathrm{mg} / \mathrm{mL}$ propidium iodide (Sigma-Aldrich, Steinheim, Germany) were prepared in ultrapure water.

\section{Four-color staining for viability assessment in mixed culture}

Cells were fluorescently stained with established fourcolor staining protocol. Briefly, after preparation, cell suspensions were incubated with $20 \mu \mathrm{g} / \mathrm{mL}$ WGA-CF405S for $15 \mathrm{~min}$ in the dark at RT. Thereafter, suspensions were washed twice applying centrifugation at 4,700 $\times \mathrm{g}$ for $10 \mathrm{~min}$ at $4^{\circ} \mathrm{C}$ (Heraeus ${ }^{\oplus}$ Fresco, Thermo Scientific, Waltham, WA, USA) and resuspension in Ringer solution. Subsequently, pelleted cells were resuspended in working solution of $1^{\circ} \mathrm{Ab}(10 \mu \mathrm{g} / \mathrm{mL}$, final $)$ and incubated for $1 \mathrm{~h}$ on ice. Afterwards, suspensions were washed as described above. Thereafter, cells were resuspended in working solution of R-PE conjugated $2^{\circ} \mathrm{Ab}(60 \mu \mathrm{g} / \mathrm{mL}$, final $)$ and incubated for $1 \mathrm{~h}$ on ice. After washing, cells were resuspended in Ringer solution and incubated simultaneously with SYBR Green I (dilution $\left.5 \times 10^{3}\right)$ and PI $(5 \mu \mathrm{g} / \mathrm{mL})$ for 20 min in the dark at RT.

In addition, SYBR Green I/PI double-stained controls were processed for each species (same washing procedure as described above). For this, untreated as well as isopropanol-treated cells (positive controls) from both exponential $(t=4 h)$ and stationary growth phases $(t=12 h)$ were used.

\section{Flow cytometry}

In this study, a CyFlow ${ }^{\circ}$ space flow cytometer (Partec, Münster, Germany) equipped with a 16 mW 375 nm UV diode laser and a $20 \mathrm{~mW} 488 \mathrm{~nm}$ argon solid state laser was used for flow cytometric analysis. Forward (FSC) and side scatter (SSC) signals were collected at $488 \mathrm{~nm}$. To reduce electronic background noise during analysis, SSC was defined as a discriminator. Threshold value was set to a lower limit of 300 (channel value) at a voltage of SSC of $260 \mathrm{mV}$. Fluorescence of WGA-CF405S was excited by the $375 \mathrm{~nm}$ laser and collected through a $455 / 50 \mathrm{~nm}$ band pass (BP) filter. R-PE immunofluorescence, SYBR Green I and PI fluorescence were excited by the $488 \mathrm{~nm}$ laser and collected through a 590/50 nm $\mathrm{BP}, 527 / 30 \mathrm{~nm}$ BP or a $630 \mathrm{~nm}$ long pass filter, respectively. Detected signals were amplified logarithmically (4 decades).

Degassed ultrapure water was applied as sheath fluid. Analysis was carried out with a sampling rate in the range of 100 to 1,000 particles/s. Samples were diluted accordingly with sheath fluid prior to analysis. To increase statistical significance, the total number of particles analyzed was set to 20,000 events for pure culture and to a minimum of 20,000 events for mixed culture samples, respectively. Data was collected with FloMax software (Version 2.70, Partec, Münster, Germany).

\section{Flow cytometric data analysis}

Analysis, compensation and gating of data were performed using FlowJo software (Version 7.6.4, Tree Star Ashland, OR, USA). Due to spectral overlapping, fluorescence signals of SYBR Green I, R-PE and PI were compensated. Therefore, for every species, single-stained controls were processed in each experiment with the respective dye or fluorescence conjugate. PI single-stained controls were performed with isopropanol-treated cells. Compensation matrices were determined based on positive fluorescence signals of single-stained controls and subsequently applied for data analysis.

Flow cytometric data is presented in 2-D graphs either in pseudo color dot plots or in 5\% quantile contour plots. Fluorescence intensities are given as relative fluorescence units (RFU).

For determination of species-specific viability, manually set gates were applied based on control samples. To discriminate cells from background, a gate for cell detection was applied. Only events with SYBR Green I positive fluorescence (intensities $\geq 1 \mathrm{RFU}$ ) were referred to as cells. Single species were detected based on WGA-CF405S fluorescence and R-PE immunofluorescence signals using a fixed gate for species discrimination. Subsequently, for each species, viability subpopulations were detected based on SYBR Green I and PI fluorescence signals. Applied viability gates were defined separately for each species for each exponential and stationary growth phase. Taking WGA-associated aggregation of $S$. aureus cells into account, for this strain, an additional gate for viability detection of single cells was used. This gate was set manually 
based on scatter signals (SSC vs FSC) of a SYBR Green I/ PI double-stained sample from pure culture, which showed predominantly single cells.

\section{Species-specific cell concentrations by qT-RFLP}

Growth of pure and mixed culture was determined by quantitation of species-specific cell concentrations using qT-RFLP analysis. Samples were treated and analyzed according to the description of Schmidt et al. [8]. Briefly, two samples were taken at each sampling point during cultivation and analyzed in parallel. $1 \mathrm{~mL}$ of sample was mixed with an internal quantification standard (IQS), an aliquot of Campylobacter jejuni with a fixed cell concentration. DNA of mixed sample was extracted by enzymatic cell lysis followed by DNA purification applying a commercially available kit (QIAamp DNA Blood Mini Kit, QIAGEN, Hilden, Germany). 16S rRNA genes were amplified by a gene-specific and fluorescently labeled primer using Polymerase Chain Reaction (PCR) method. Amplicons were then purified using an agarose gel and a commercially available extraction kit (QIAquick Gel Extraction Kit, QIAGEN, Hilden, Germany). Subsequently, amplicons were restricted with an $\mathrm{HhaI}$ endonuclease (R0139L, New England Biolabs Inc., Ipswich, MA, USA). Finally, species-specific rDNA fragments were separated by capillary gel electrophoresis and detected by laser-induced fluorescence (CGE-LIF) using a Genetic Analyzer ABI Prism 3100 Avant (Life Technologies, Carlsbad, CA, USA).

Species-specific cell concentration was determined by calculating the ratio of detected peak area for the given species to the peak area of the IQS $[7,8]$. Concentrations were declared as genome equivalents per $\mathrm{mL}(\mathrm{ge} / \mathrm{mL})$ as described previously by Riedele and Reichl [10].

\section{Analysis of substrates and metabolites}

Samples were harvested by centrifugation at $16,200 \times \mathrm{g}$ for $10 \mathrm{~min}$ at $4^{\circ} \mathrm{C}$ (Heraeus ${ }^{\oplus}$ Fresco, Thermo Scientific Waltham, WA, USA). Supernatants were withdrawn and filtrated using a syringe (Injekt $2 \mathrm{~mL}$, B. Braun AG, Melsungen, Germany) with a $0.2 \mu \mathrm{m}$ filter (Spartan 13/RC, Whatman $\mathrm{GmbH}$, Dassel, Germany), and stored at $4{ }^{\circ} \mathrm{C}$ until analysis.

Extracellular concentrations of glucose, glutamate and glutamine in the culture medium were determined according to a protocol of Riedele and Reichl [28] with a validated enzymatic quantification method using a Bioprofile 100 Plus (Nova Biomedical, Waltham, MA, USA). Quantitation limits and standard deviation (SD) of the method were as follows: glucose: $1.022 \mathrm{mM}$, SD $0.100 \mathrm{mM}$; glutamate: $0.254 \mathrm{mM}$, SD $0.025 \mathrm{mM}$; glutamine: $0.162 \mathrm{mM}$, SD $0.016 \mathrm{mM}$.

Extracellular concentrations of metabolites 2-keto-Dgluconic acid (2-KDG) and gluconic acid released in the culture medium, were quantified by HPLC (Agilent 1200 series, Agilent Technologies, Inc., Santa Clara, CA, USA) equipped with a Rezex-ROA organic acid column $300 \times$ $7.6 \mathrm{~mm}$ (Phenomenex, Aschaffenburg, Germany). The applied method was in agreement with the method used by Riedele and Reichl [28] and comprised $0.075 \mathrm{M} \mathrm{H}_{2} \mathrm{SO}_{4}$ as eluent with a flow rate of $0.5 \mathrm{~mL} / \mathrm{min}$. From each sample $10 \mu \mathrm{L}$ were injected and separation was performed at $45^{\circ} \mathrm{C}$ (column). Metabolites were detected by a diode array detector (DAD G1315B, Agilent Technologies, Inc., Santa Clara, CA, USA) at $210 \mathrm{~nm}$. Quantitation limits and SD of the method were as follows: 2-KDG: $0.155 \mathrm{mM}$, SD $0.016 \mathrm{mM}$; gluconic acid: $0.267 \mathrm{mM}$, SD $0.026 \mathrm{mM}$.

\section{Statistical testing}

To compare results obtained under different (mixed versus pure culture) or identical cultivation conditions, either unpaired or paired Student $t$-tests $(\mathrm{p}<0.05)$ were performed, respectively.

\section{Results}

\section{Characterization of viability using flow cytometry}

Viability was determined by membrane integrity analysis using flow cytometry. Therefore, nucleic acid doublestaining (NADS) was applied, comprising PI for identification of dead cells and SYBR Green I for total cell staining. Staining conditions $\left(5 \mu \mathrm{g} / \mathrm{mL}\right.$ PI; $5 \times 10^{3}$ SYBR Green I dilution; $\mathrm{NaCl}$ phosphate buffer containing $0.05 \mathrm{mg} / \mathrm{mL}$ GTA) were chosen according to an optimized method for viability analysis of $S$. aureus and B. cepacia in mixed culture published recently [26]. However, since PI staining of $P$. aeruginosa in $\mathrm{NaCl}$ phosphate buffer ( $\mathrm{NaCl}-\mathrm{P})$ led to a total loss of membrane integrity (Figure 1(A)), this buffer was replaced by Ringer solution containing GTA. Remarkably, the addition of GTA did not impair membrane integrity of $P$. aeruginosa (Figure 1(B)). The modified double-staining protocol enabled reproducibly the detection of characteristic viability subpopulations of each species. Dead cells with permeabilized membranes and viable cells with intact membranes were detected based on green and red fluorescence (Figure 2). Viable cells displayed SYBR Green I fluorescence and no PI fluorescence, whereas dead cells showed intense PI fluorescence as well as SYBR Green I fluorescence. Remarkably, fluorescence intensities varied between species after staining, particularly with respect to SYBR Green I. The existence of dead cells was verified by staining of cells treated with $70 \%$ $(\mathrm{v} / \mathrm{v})$ isopropanol (positive controls), which resulted in identical fluorescence signals compared to the subpopulation of dead cells in untreated samples. For S. aureus, an additional subpopulation was detected, which was referred to as "cells with slightly damaged membranes" (damaged) as described previously [26]. In comparison to the staining method established previously in $\mathrm{NaCl}$ phosphate buffer [26], similar values were determined for the frequency of 



Figure 1 Comparison of $\mathrm{NaCl}-\mathrm{P}$ buffer and Ringer solution in viability determination of $P$. aeruginosa by flow cytometry. (A) Relative frequencies of PI stained cells $(5 \mu \mathrm{g} / \mathrm{mL}$ ) for stationary grown $P$. aeruginosa from pure culture in NaCl-P buffer and Ringer solution at different dye incubation times. (B) Relative frequencies of PI stained cells in exponential and stationary growth phases from pure culture prepared in Ringer solution without GTA and with $0.05 \mathrm{mg} / \mathrm{mL}$ GTA. Relative frequency of PI stained cells was determined by ratio of relative frequency of PI stained events in untreated and isopropanol-treated samples. Error bars represent standard deviation of three biological replicates; \# indicates a statistically significant difference $(p<0.05$, paired Student $t$-test).

viable and dead cells of B. cepacia (Figure 3(A)) as well as viable, damaged and dead cells of $S$. aureus (Figure 3(B)) in pure culture using Ringer solution.

\section{Species-specific viability analysis in mixed culture}

For determination of species-specific viability in defined mixed cultures, comprising three bacterial species relevant to lung infections of CF patients by flow cytometry, a four-color staining method was established. Therefore, a previously presented method for binary mixed cultures [26], comprising Gram-specific fluorescence labeling of $S$. aureus using CF405S-conjugated WGA in combination with NADS, was extended to enable indirect immunofluorescence labeling of $B$. cepacia. Two monoclonal antibodies were used, a primary antibody mouse antiPseudomonas cepacia $\left(1^{\circ} \mathrm{Ab}\right)$ and a secondary antibody goat anti-mouse conjugated with R-PE $\left(2^{\circ} \mathrm{Ab}\right)$. In contrast to the method published previously, Ringer solution was applied instead of NaCl-P buffer. For efficient discrimination of WGA CF405S labeled S. aureus from unlabeled $P$. aeruginosa and B. cepacia, $3 \mathrm{M} \mathrm{KCL}$ had to be added to the Ringer solution, which resulted in an increased fluorescence signal of WGA labeling as described previously in the study of Holm et al. [29]. That the addition of $\mathrm{KCl}$ did not impair membrane integrity of single species during analysis was tested beforehand by SYBR Green I and PI double-staining experiments using pure cultures. In particular, relative frequencies of viable and dead cells of $P$. aeruginosa and B. cepacia, and viable, damaged, and dead cells of $S$. aureus were generally similar in comparison to frequencies determined for references without addition of $\mathrm{KCl}$ (Figure 4). The reliability of immunofluorescence
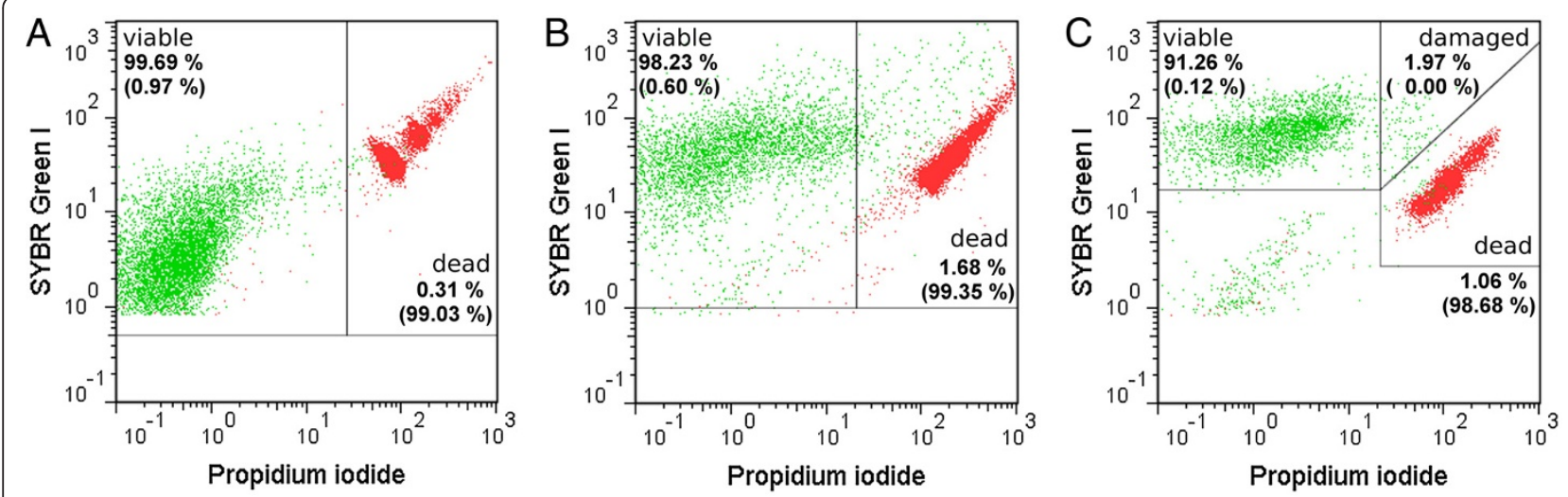

Figure 2 Viability analysis by flow cytometry. Viability was determined by membrane integrity analysis using SYBR Green I (dilution of $5 \times 10^{3}$ ) and PI (5 $\mu \mathrm{g} / \mathrm{mL})$. Representative pseudo color dot plots with defined gates are shown for (A) P. aeruginosa, (B) B. cepacia and (C) S. aureus in stationary growth phase $(t=12 \mathrm{~h}$ ) from pure culture. Gates were set manually for each species based on SYBR Green I and PI fluorescence signals of isopropanol-treated (red) and untreated cells (green). For each gate region, relative frequencies of total cells are presented. Only events with positive SYBR Green I fluorescence were considered as cells (see Figure 7). 

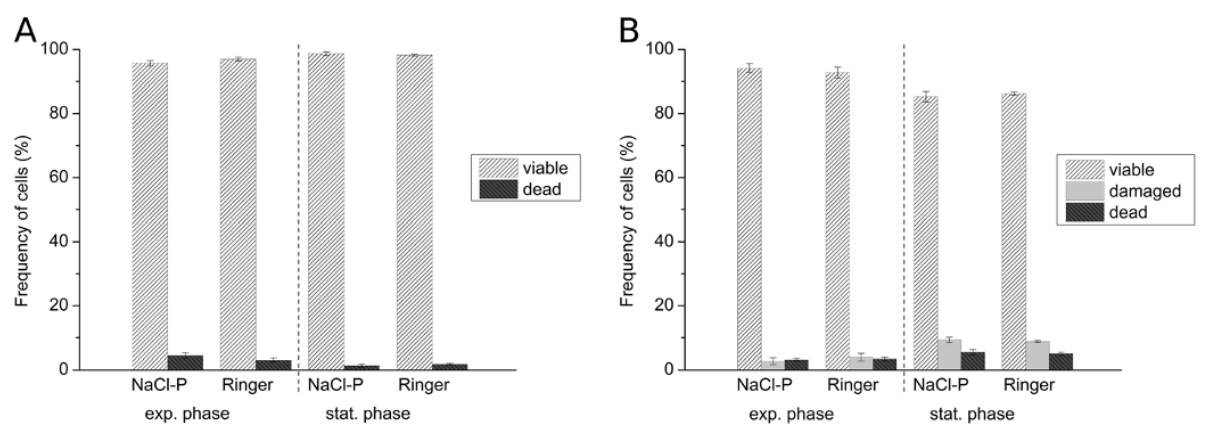

Figure 3 Comparison of NaCl-P buffer and Ringer solution for viability analysis of B. cepacia and S. aureus by flow cytometry. Viability was determined by membrane integrity analysis using SYBR Green I (dilution of $\left.5 \times 10^{3}\right)$ and PI $(5 \mu \mathrm{g} / \mathrm{mL}$ ). Relative frequencies of (A) viable and dead cells of B. cepacia and (B) of viable, damaged and dead cells of $S$. aureus in pure culture from both exponential and stationary growth phase. Relative frequencies were determined based on all SYBR Green I and PI fluorescence positive events. Error bars represent standard deviation of three biological replicates.

labeling for specific detection of B. cepacia was tested beforehand by single-staining experiments of pure culture samples using flow cytometry and fluorescence microscopy. For testing, a combination of $5 \mu \mathrm{g} / \mathrm{mL} 1^{\circ} \mathrm{Ab}$ and $20 \mu \mathrm{g} / \mathrm{mL}$ $2^{\circ} \mathrm{Ab}$ as well as use of $2^{\circ} \mathrm{Ab}$ alone were applied. Immunofluorescence testing revealed for $1^{\circ} \mathrm{Ab}$ efficient binding to $B$. cepacia, no binding to $P$. aeruginosa and unspecific binding to $S$. aureus. Moreover, $2^{\circ} \mathrm{Ab}$ did neither bind to B. cepacia nor to $P$. aeruginosa, but bound unspecifically to S. aureus (Figures 5 and 6 ). Thus, indirect immunolabeling of B. cepacia using both antibodies resulted in intense R-PE fluorescence staining of B. cepacia. However, in mixed culture, fluorescence signals of immunolabeled S. aureus interfered with immunofluorescence signals of $B$. cepacia. Despite of this, the tested immunolabeling procedure was demonstrated to be highly efficient for species detection in mixed culture; in particular, when combined with WGACF405S staining of $S$. aureus and total cell staining, with SYBR Green I and PI. For data analysis, only events with SYBR Green I positive fluorescence (cells) were considered (Figure 7(A)). Due to efficient Gram-specific staining of
S. aureus, neither $P$. aeruginosa nor $B$. cepacia were stained with WGA-CF405S by applying four-color staining (Figure 7(B)). Therefore, all three species could be detected specifically in mixed culture by four-color staining by adequate discrimination according to WGA-CF405S fluorescence and R-PE immunofluorescence signals (Figure 7(C)). For reproducible and efficient species discrimination for all mixed culture samples, a fixed gate was applied, which was defined manually according to signals obtained in pure culture experiments (Figure 7(B)). As a result, the gating of four-color stained cells from pure culture enabled to obtain cell recoveries above $98 \%$ for $P$. aeruginosa, above $94 \%$ for S. aureus and above $93 \%$ for B. cepacia throughout the cultivation period covered in the performed cultivations $(t=32$ h). Exceptions were found for B. cepacia during exponential growth phase $(t=4 \mathrm{~h})$. Here, the cell recovery was only about $78 \%$ (mean value from three biological replicates). Overall, the species discrimination based on gating allowed then for efficient determination of species-specific viability in the three-species mixed culture according to SYBR Green I and PI fluorescence signals. For each species,
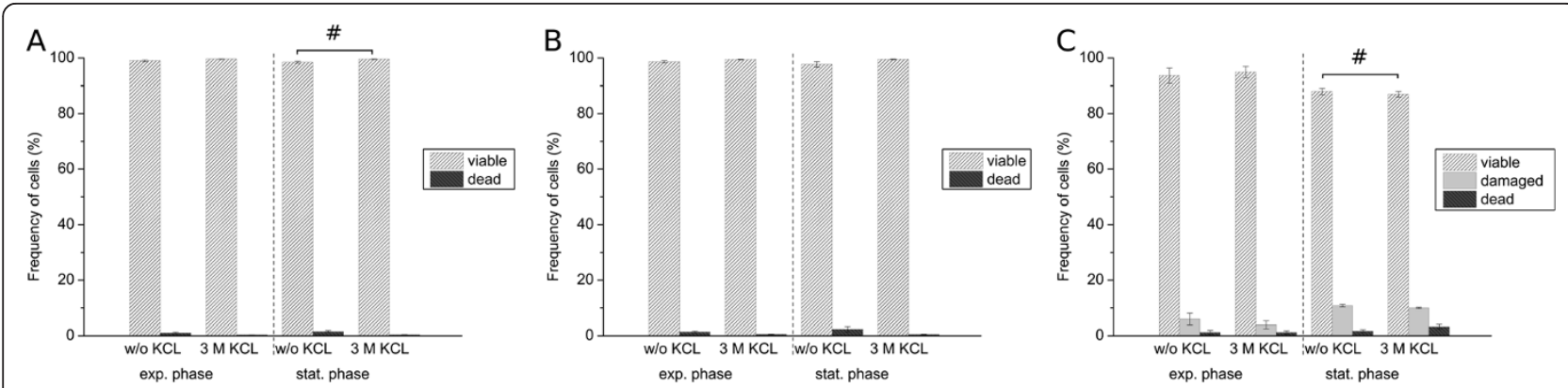

Figure 4 Impact of KCL on flow cytometric viability determination. Comparison of Ringer solution without and with $3 \mathrm{M} \mathrm{KCl}$. Viability was determined by membrane integrity analysis using SYBR Green I (dilution of $\left.5 \times 10^{3}\right)$ and PI $(5 \mu \mathrm{g} / \mathrm{mL}$ ). Relative frequencies of (A) viable and dead cells of P. aeruginosa, (B) of viable and dead cells of B. cepacia and (C) of viable, damaged and dead cells of $S$. aureus in exponential and stationary growth phases in pure culture. Relative frequencies were determined based on all SYBR Green I and PI fluorescence positive events. Error bars represent standard deviation of three biological replicates; \# indicates a statistically significant difference $(p<0.05$, paired Student $t$-test). 

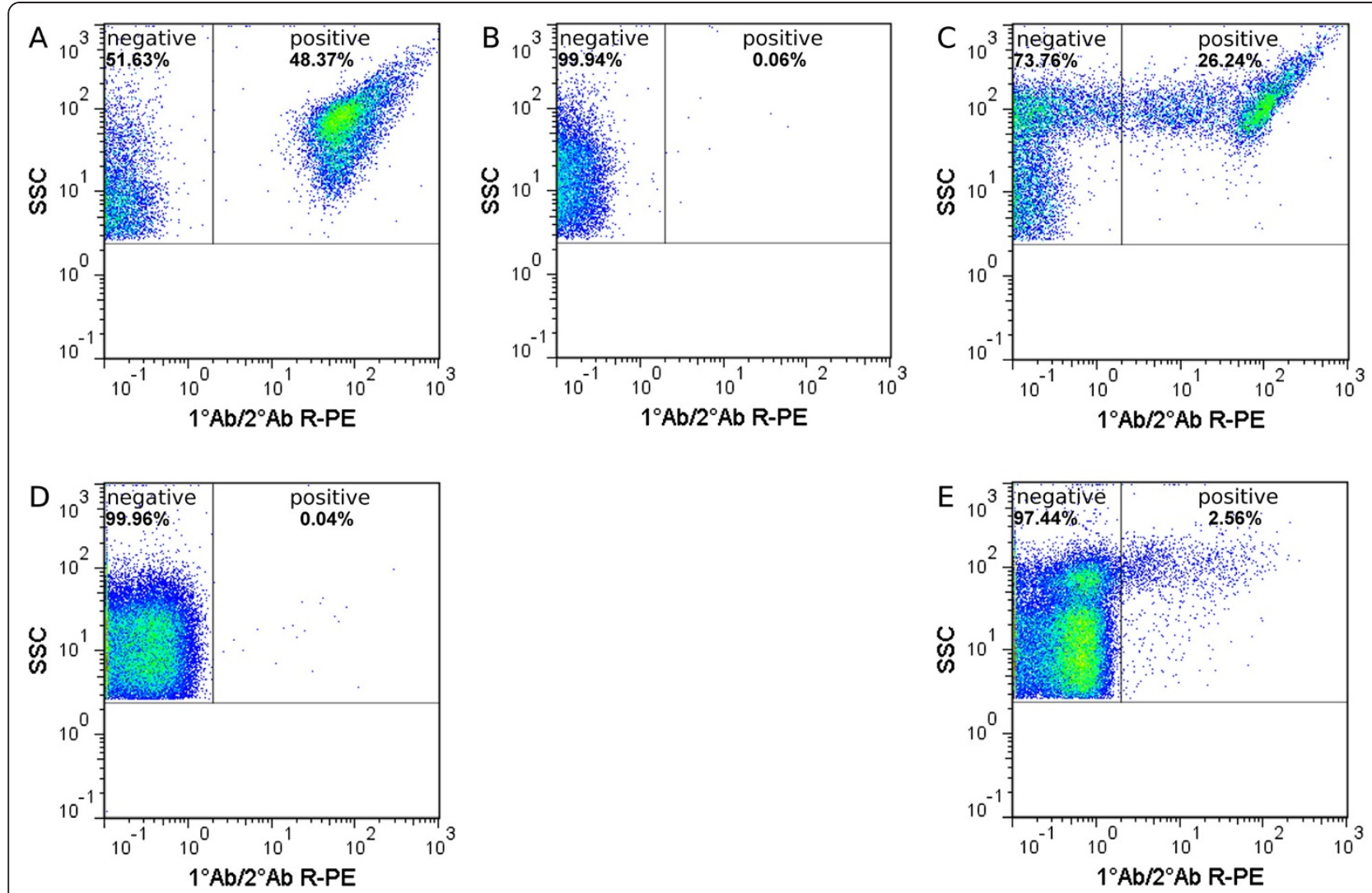

Figure 5 Immunofluorescence testing by flow cytometry. $5 \mu \mathrm{g} / \mathrm{mL} 1^{\circ} \mathrm{Ab}$ and $20 \mu \mathrm{g} / \mathrm{mL}$ R-PE conjugated $2^{\circ} \mathrm{Ab}$ were used representative pseudo color dot plots for (A) B. cepacia, (B) P. aeruginosa and (C) S. aureus in exponential growth phase ( $\mathrm{t}=2 \mathrm{~h}$ ) from pure cultures. Additionally for species with positive immunofluorescence signal using $1^{\circ} \mathrm{Ab}$ and $2^{\circ} \mathrm{Ab}$, binding of $2^{\circ} \mathrm{Ab}$ alone was tested: (D) B. cepacia and (E) S. aureus. Gates were set manually based on R-PE fluorescence signal of unstained and stained cells. For each gate, relative frequencies of total events are presented.

relative frequencies of viability subpopulations were determined by respective species-specific gating (Figure 2).

\section{Assessment of growth and viability in pure and mixed culture cultivations}

Viability of $P$. aeruginosa, B. cepacia and $S$. aureus was assessed by membrane integrity analysis during growth in pure and mixed culture cultivations, using the established four-color staining method and flow cytometry. Additionally, to characterize growth of single species, species-specific cell concentrations were determined by qT-RFLP. Comparison between dynamics of cell concentrations in mixed and pure cultures revealed differences for every species in growth properties (Figure 8(A, C, E)).
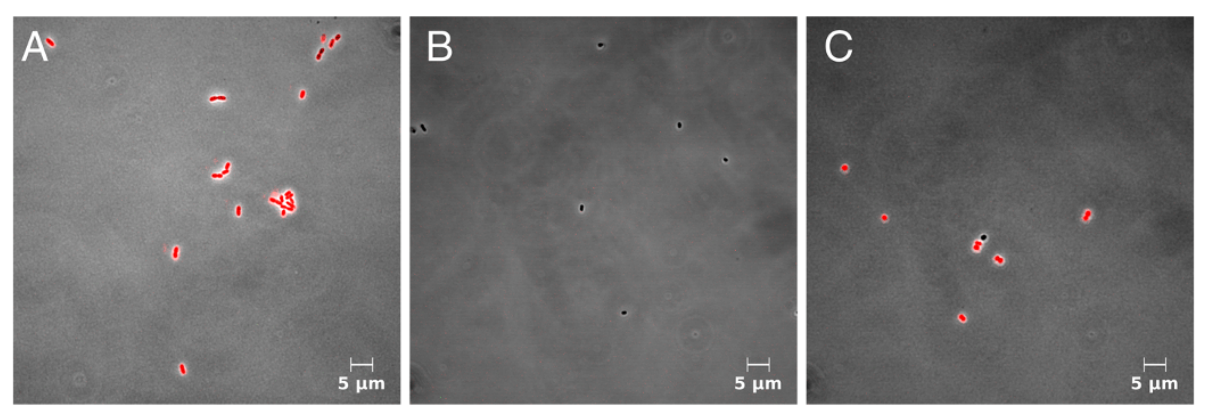

Figure 6 Immunofluorescence testing by fluorescence microscopy. $5 \mu \mathrm{g} / \mathrm{mL} 1^{\circ} \mathrm{Ab}$ and $20 \mu \mathrm{g} / \mathrm{mL}$ R-PE conjugated $2^{\circ} \mathrm{Ab}$ were used representative microscopic images for (A) B. cepacia, (B) P. aeruginosa and (C) S. aureus in exponential growth phase ( $t=2 \mathrm{~h})$ from pure cultures. Laser Scanning Microscopy was employed (LSM 510, Carl Zeiss AG, Oberkochen, Germany). R-PE fluorescence was excited by $1 \mathrm{~mW} 543 \mathrm{~nm}$ Helium-Neon Laser and collected through a $585 \mathrm{~nm}$ long pass filter. Images are magnified $1000 \mathrm{x}$. 

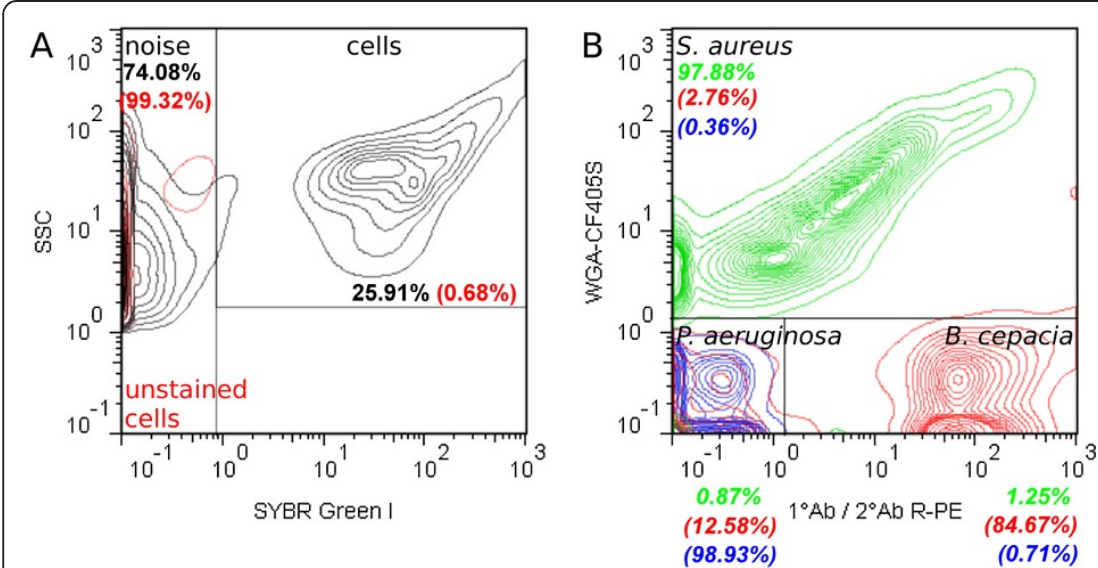

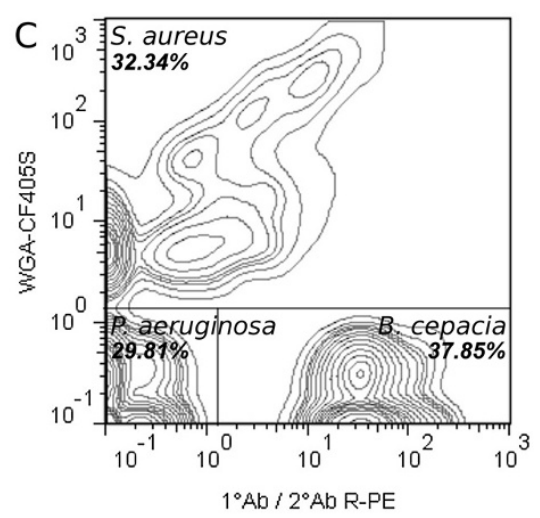

Figure 7 Species discrimination in flow cytometric viability analysis. Four-color staining was applied. Samples were incubated with $20 \mu \mathrm{g} / \mathrm{mL}$ WGA-CF405S, $10 \mu \mathrm{g} / \mathrm{mL} 1^{\circ} \mathrm{Ab}$ and $60 \mu \mathrm{g} / \mathrm{mL}$ R-PE conjugated $2^{\circ} \mathrm{Ab}$, SYBR Green I (dilution of $5 \times 10^{3}$ ) and $5 \mu \mathrm{g} / \mathrm{mL}$ PI. (A) For data analysis, only events with SYBR Green I positive fluorescence (cells) were considered. The cell gate was set manually based on the signal of four-color-stained (black) and unstained cells (red) in exponential growth phase $(t=4 \mathrm{~h})$ from pure culture. (B, C) Gating for species discrimination in data acquired from mixed culture samples. Gate was set manually based on WGA-CF405S fluorescence and R-PE immunofluorescence signals of four-color-stained single species from pure culture. (B) Overlaid cytometric plot of $P$. aeruginosa (blue), B. cepacia (red) and S. aureus (green) in exponential growth phase ( $\mathrm{t}=4 \mathrm{~h}$ ) from pure culture. (C) Gate applied for species discrimination in mixed culture sample at time point of inoculation. For each gate region, either relative frequencies of total events or cells (in italics) are shown. Data is presented in 5\% quantile contour plots.

For $P$. aeruginosa, growth was improved in mixed culture. Cells grew faster with a significant higher maximum specific growth rate $(\mathrm{p}<0.05$, unpaired Student $t$-test; Table 1). With $6 \mathrm{~h}$ the exponential growth phase took also longer than in pure culture. Consequently, the maximum cell concentration $\left(\log _{10} 8.47 \pm 0.23 \mathrm{ge} / \mathrm{mL}\right)$ was higher than in pure culture (Figure $8(\mathrm{~A})$ ). For B. cepacia, growth dynamics were similar for the first $6 \mathrm{~h}$ of cultivation in pure and mixed culture (Figure $8(\mathrm{C})$ ). Also, the maximum specific growth rates were comparable (Table 1). However, after $6 \mathrm{~h}$ time courses differed significantly from each other. In mixed culture, growth remained static until $12 \mathrm{~h}$ before cell concentration decreased slightly towards the end of cultivation. In contrast, in pure culture, cell concentration increased until the end of experiment. The maximum cell concentration in pure culture $\left(\log _{10} 8.20 \pm\right.$ $0.20 \mathrm{ge} / \mathrm{mL}$ ) was almost two-log levels higher than in mixed culture (Figure $8(\mathrm{C})$ ). For $S$. aureus, time course of cell concentrations were comparable for the first $12 \mathrm{~h}$ of cultivation in pure culture and mixed culture (Figure $8(\mathrm{E})$ ). Maximum specific growth rates (Table 1) as well as maximum cell concentrations were also similar. However, after $12 \mathrm{~h}$ time courses differed from each other. In mixed culture cell concentrations decreased slightly until the end of cultivation, whereas concentrations in pure culture remained relatively constant (Figure $8(\mathrm{E})$ ).

For $P$. aeruginosa, the viability in pure and mixed culture was initially high at about 99\%. Then it remained relatively constant before decreasing after $12 \mathrm{~h}$ to achieve about 73\% towards the end of cultivation (Figure 8(B)). For B. cepacia, viability in pure and mixed culture was as high as for $P$. aeruginosa in the beginning. However, viability was reduced during exponential growth phase after $4 \mathrm{~h}$ to about $89 \%$ in pure or $80 \%$ in mixed culture, respectively. Subsequently, viability increased in both cultures to a level of about $98 \%$ to remain constant from $8 \mathrm{~h}$ to $12 \mathrm{~h}$ (Figure 8(D)). Afterwards, viability decreased in both cultures slightly towards the end of cultivation. For S. aureus, the viability in pure and mixed culture was initially as high as determined for the Gram-negative bacteria. Viability differed slightly between pure and mixed culture during exponential growth phase $(0 \mathrm{~h}$ to $4 \mathrm{~h})$. However, at $8 \mathrm{~h}$, viabilities achieved again similar levels of about $98 \%$. Afterwards, the time course of viability of S. aureus differed significantly between pure and mixed cultures (Figure 8(F)). Although viability decreased in both cultures towards the end of cultivation, in mixed culture, it decreased earlier than in pure culture and initially at a faster rate. Briefly, viability in mixed culture dropped instantly from $8 \mathrm{~h}$ to $12 \mathrm{~h}$ to about $47 \%$, whereas viability in pure culture remained high at about $97 \%$. Afterwards, viability decreased continuously in both cultures to levels of about $13 \%$. The frequency of dead cells of S. aureus in pure and mixed culture correlated well with the time course of viable cells over a cultivation period of $24 \mathrm{~h}$ or $12 \mathrm{~h}$, respectively. Remarkably, for S. aureus in mixed culture, loss of viability resulted first in an increase of damaged cells and subsequent in an increase of dead cells, whereas in pure culture, damaged cells increased with dead cells. However, in both cultures, damaged cells decreased towards the end of cultivation, whereas dead cells continued increasing. 

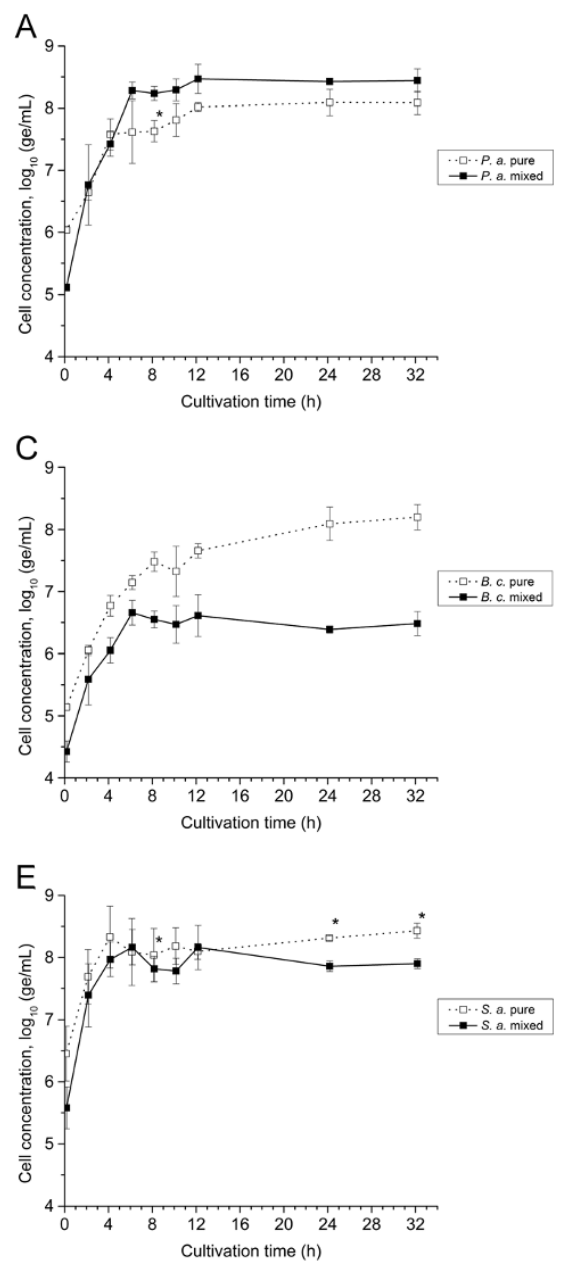

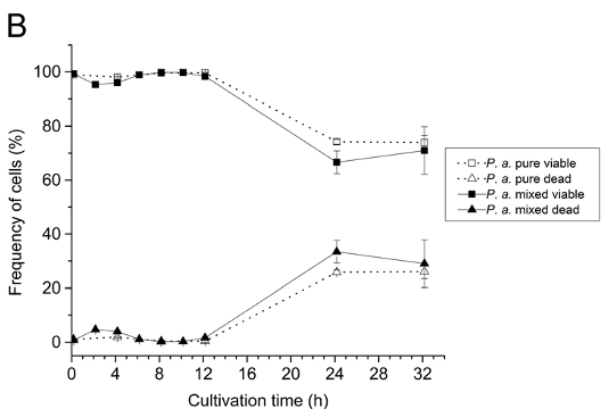

D
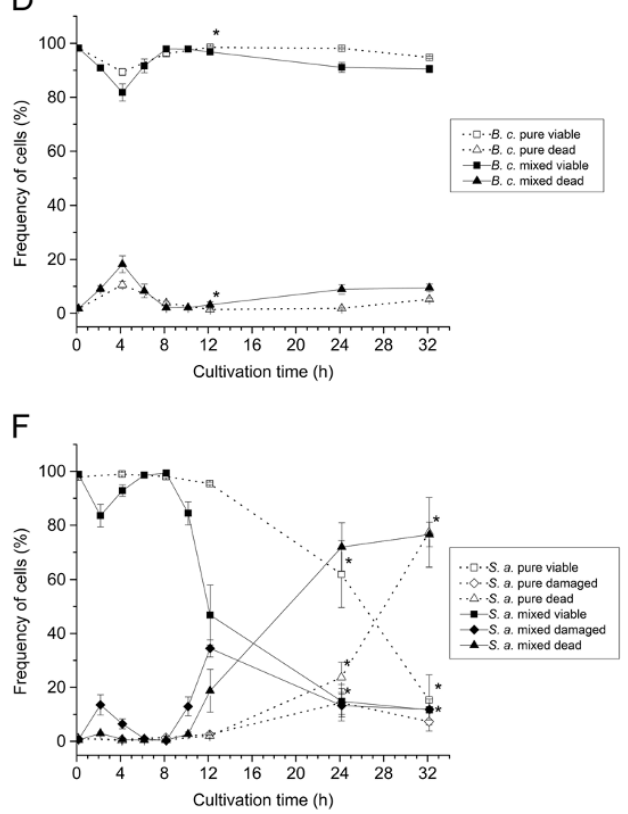

Figure 8 Growth and viability in pure and mixed cultures. Species-specific cell concentrations and viability were determined over a cultivation period of $32 \mathrm{~h}$ by qT-RFLP and flow cytometry, respectively. Open symbols represent data from pure cultures and filled symbols from mixed culture. Left: Dynamics of $\log _{10}$-transformed species-specific cell concentrations of (A) P. aeruginosa, (C) B. cepacia, and (E) S. aureus. Right: Dynamics of relative frequencies of (B) viable and dead cells of P. aeruginosa, (D) viable and dead cells of B. cepacia and (F) viable, damaged and dead cells of $S$. aureus. Relative frequencies of viability subpopulations were determined based on all SYBR Green I and PI fluorescence positive events in the respective species gate. Subpopulations were defined as gated in plots shown in Figure 2. Error bars represent standard deviation of two (*) or three biological replicates.

Table 1 Maximum specific growth rates $\mu_{\max }$ in pure and mixed culture

\begin{tabular}{llllll}
\hline Species & \multicolumn{2}{l}{ Pure culture } & & \multicolumn{2}{c}{ Mixed culture } \\
\cline { 2 - 3 } & $\boldsymbol{\mu}_{\max }\left(\mathbf{h}^{-\mathbf{1}}\right)$ & $\boldsymbol{\Delta} \mathbf{t}(\mathbf{h})$ & & $\boldsymbol{\mu}_{\max }\left(\mathbf{h}^{-\mathbf{1}}\right)$ & $\boldsymbol{\Delta t} \mathbf{( h )}$ \\
\hline P. a. & $0.88 \pm 0.11$ & $0-4$ & & $1.22 \pm 0.05$ & $0-6$ \\
B. c. & $0.77 \pm 0.02$ & $0-6$ & & $0.86 \pm 0.09$ & $0-6$ \\
S. a. & $1.08 \pm 0.37$ & $0-4$ & & $1.29 \pm 0.31$ & $0-4$ \\
\hline
\end{tabular}

Parameters were determined for $P$. aeruginosa, B. cepacia and S. aureus by linear regression from $\log _{\mathrm{e}}$ cell concentrations during exponential growth phase; mean values \pm standard deviation from three biological replicates.
To investigate the impact of substrate availability on growth and viability of single species, concentrations of main substrates and metabolites released in the culture medium were quantified in pure and mixed cultures during the first $12 \mathrm{~h}$ of cultivation. Glucose, glutamine and glutamate were consumed completely by all species within $8 \mathrm{~h}$ in pure and mixed culture (Figure 9). Interestingly, glutamine and glutamate were consumed faster by $P$. aeruginosa than by $B$. cepacia and $S$. aureus in pure culture. In mixed culture, glutamine was consumed as fast as observed in pure culture of $P$. aeruginosa. Gluconate and 2-KDG were produced in pure cultures of $P$. aeruginosa and $B$. cepacia as well as in mixed cultures during the first $8 \mathrm{~h}$ of cultivation (Figure 9(B)). Remarkably, these metabolites were consumed by $P$. aeruginosa and B. cepacia 

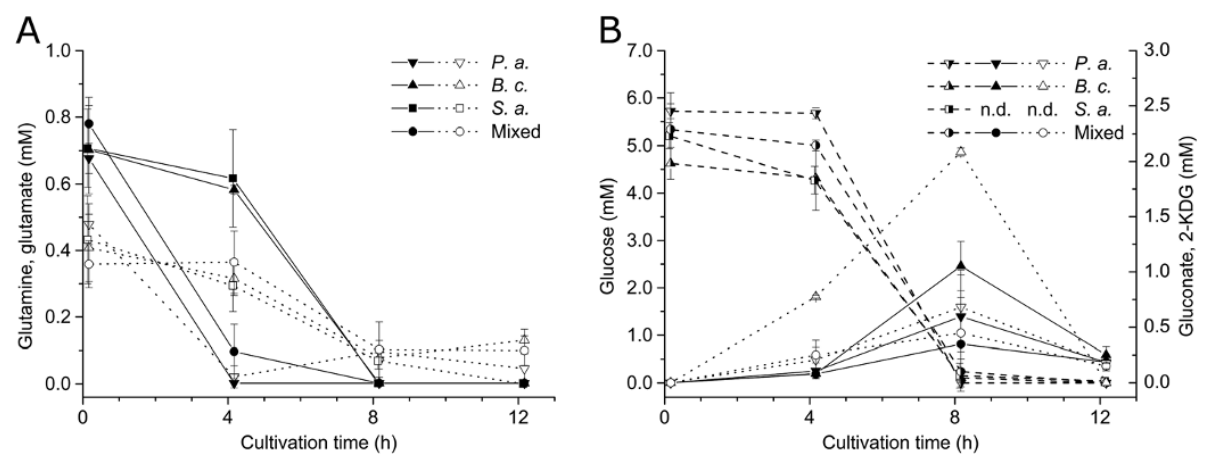

Figure 9 Extracellular substrate and metabolite concentrations in pure and mixed cultures. Glutamine, glutamate and glucose were quantified by an enzymatic assay. Gluconate and 2-KDG were quantified by HPLC. Time courses of (A) glutamine (filled symbols) and glutamate (open symbols) and (B) glucose (half-filled symbols), 2-KDG (filled symbols) and gluconate (open symbols) are presented over a cultivation period of $12 \mathrm{~h}$. For S. aureus neither gluconate nor 2-KDG were detected (n.d., below detection limit). Error bars represent standard deviation of three biological replicates.

in pure culture. Moreover, gluconate and 2-KDG were also consumed in mixed cultures.

\section{Discussion}

Species-specific determination of viability by flow cytometry In this study, flow cytometry has been shown to be a highly capable technique for efficient determination of species-specific viability of $P$. aeruginosa, $B$. cepacia and $S$. aureus in defined mixed cultures relevant to lung infections of CF patients. Even though, a combination of the applied qT-RFLP method with PMA pre-treatment may enable detection of viable cells, in this study, the use of flow cytometry was preferred for viability analysis due to two practical limitations of PMA-T-RFLP: First, cells with slightly damaged membranes, which may occur during growth due to short-term perforation of the cell wall during cell division and cell wall synthesis [13], cannot be discriminated by PMA-T-RFLP from viable cells or dead cells, respectively. Second, quantification of viable cells by T-RFLP using PMA pre-treatment can be affected by the presence of a high number of dead cells in the sample (see review [14]), in particular, with a concentration of dead cells exceeding $10^{4}$ cells $/ \mathrm{mL}$ [30-33].

Viability was determined by flow cytometry assessing the membrane integrity of cells using an adapted NADS protocol (see Methods). PI was applied for identification of dead cells in combination with SYBR Green I for total cell staining. For each species, the protocol enabled detection of dead and viable cells with permeabilized or intact membranes, respectively. It is assumed that the loss of membrane integrity is associated with missing reproductive growth and missing metabolic activity and eventually leads to cell death [34]. Thus, cells labeled as viable can be metabolically active or inactive as well as culturable or non-culturable cells. PI fluorescence signal intensities of dead cells increased most likely by quenching from SYBR Green I to PI when cells are double-stained
[35]. Fluorescence intensities of viable and dead cells varied between species, which can be largely attributed to differences in cell wall structure [13], total DNA content and base composition [36], as well as in efflux pump activity [26]. Weak SYBR Green I fluorescence intensities, especially for viable cells of $P$. aeruginosa, suggest an outpumping of dye from cells by active efflux pumps. In contrast, dead cells of $P$. aeruginosa exhibited intense SYBR Green I fluorescence, which is most likely due to missing efflux activity when membranes are permeabilized. For S. aureus, damaged cells were additionally detected, which were referred to as "cells with a slightly damaged membrane" by taking results of other authors $[16,23]$ into account. These cells are probably stained with a low amount of PI resulting in incomplete quenching from SYBR Green I to PI [35].

For assessment of species-specific viability in mixed cultures, Gram-specific staining of S. aureus and indirect immunolabeling of $B$. cepacia using fluorescently labeled WGA and monoclonal antibodies, respectively, were employed successfully in combination with the adapted NADS protocol. However, the establishment of the method was very time consuming, since every single staining condition had to be tested separately for each bacterial species. Moreover, such an approach can only be applied for bacteria cultivable in pure culture, since labels and viability dyes need to be tested a priori for each species. Thus, the use of such technique is restricted to defined mixed cultures. The established four-color staining method allowed for efficient specific detection of $P$. aeruginosa, B. cepacia and $S$. aureus in mixed culture samples and subsequent determination of viability. WGA was shown to bind exclusively to $S$. aureus, most likely to the outer peptidoglycan layer of the cell wall, since it is known to bind specifically to $\mathrm{N}$-acetylglucosamine and $\mathrm{N}$-acetylneuroaminic residues [37]. The fact that WGA does not bind to Gram-negative bacteria in mixed culture is most probably attributed to 
the presence of an outer membrane [38]. WGA staining of $S$. aureus was as efficient and reproducible as presented in a previously published report for specific detection of $S$. aureus in binary mixed cultures [26]. Moreover, the binding capacity of WGA remained stable over the time period covered in the conducted cultivations, as demonstrated in pure culture. Indirect immunolabeling allowed for efficient specific detection of B. cepacia in mixed culture samples, when four-color staining method was applied. Cross reaction of both monoclonal antibodies to $S$. aureus was also observed, and is most probably attributed to the presence of protein $\mathrm{A}$ in the cell wall of this strain. Protein A is known to react with antibodies [39,40], particularly with high affinity to immunoglobulin G [41]. Specific detection of $B$. cepacia by immunolabeling was very efficient and reproducible, but reduced recoveries were observed during the exponential growth phase. This may be explained by low accessibility of surface-exposed epitopes at proliferation. This is in agreement with conclusions made from insufficient immunofluorescence labeling of bacteria in a report of Hughes et al., who suggested a cell cycle-dependent exposure of the targeted outer membrane protein of the species of interest [42]. Overall, the cell recoveries of specifically detected species were very high for the obtained samples throughout the cultivations, as demonstrated for pure cultures. However, they were less than $100 \%$. Accordingly, with respect to species-specific labels, false negative counts of $B$. cepacia and $S$. aureus cells cannot be excluded completely. Consequently, this may have a slight impact on the detected relative frequencies of viable and dead $P$. aeruginosa. However, for the purpose of this study describing the viability dynamics in mixed culture, the specificity of this protocol was sufficiently high. For other purposes a third species-specific label may be advisable.

\section{Mixed culture effects on viability and growth}

To investigate mixed culture effects on viability and growth of the three single species, mixed culture as well as pure culture cultivations were performed. Speciesspecific viability was assessed using the established flow cytometric method. Growth of single species was assessed by quantification of species-specific cell concentrations using qT-RFLP analysis. To investigate a possible impact of cell concentrations at time point of inoculation onto dynamics in the mixed culture, cultivations were carried out with one-log-reduced starting cell concentrations in comparison to cultures conducted in the study of Riedele and Reichl [10]. However, the ratio between species in mixed culture was maintained.

For all species, analysis of cell concentrations by qTRFLP revealed clear differences in growth dynamics between mixed and pure culture. P. aeruginosa showed improved growth in mixed culture. According to conclusions drawn by Riedele and Reichl from their experiments this extended exponential growth phase is most likely due to the reduced starting cell concentrations in mixed culture compared to pure culture (see Methods), which enabled an increasing number of cell divisions while the substrate is consumed until depletion [10]. This is supported by the finding that levels of glutamine and glucose dropped below the detection limit after $4 \mathrm{~h}$ or $8 \mathrm{~h}$, respectively, following comparable time profiles in mixed and pure culture. Furthermore, in both cultures, level of gluconate dropped below the detection limit after $4 \mathrm{~h}$ or $8 \mathrm{~h}$, respectively. However, the higher specific growth rate in mixed culture compared to pure cultures may be caused by an unknown interspecies effect and remains to be identified. In case of B. cepacia, growth stagnated in mixed culture after $6 \mathrm{~h}$ of cultivation, whereas growth in pure culture was observed until the end of cultivation. These differences may be explained partially by competition for glutamine with $P$. aeruginosa during growth. This is supported by the finding that glutamine was consumed in mixed culture as fast as in pure culture of $P$. aeruginosa and thus, faster than in pure culture of B. cepacia. Furthermore, growth stagnation of B. cepacia in mixed culture may be caused by antagonistic interaction through action of inhibitory active substances against B. cepacia, e.g. pyocins, produced by P. aeruginosa. The latter could further explain the decrease of cell concentrations of B. cepacia in mixed culture towards the end of cultivation. In fact, the PAO1 strain is known to produce pyocins $[43,44]$, and its inhibitory activity against $B$. cepacia was demonstrated in a study of Bakkal et al. [45], in which different clinical strains of $B$. cepacia and $P$. aeruginosa isolated from $\mathrm{CF}$ patients were tested in mixed culture. Although Riedele and Reichl [10] suggested in their study no significant alterations for cell doublings of $B$. cepacia between growth in pure and mixed culture, the cell concentrations clearly reveal the same trend towards the end of cultivation as observed in this study. However, the mode of action of inhibitory active substances against $B$. cepacia produced by $P$. aeruginosa remains to be elucidated. Despite of this, obtained results indicate no antagonistic interactions from $S$. aureus to $P$. aeruginosa or to B. cepacia. The latter is in agreement with findings of a previously published study, in which these strains were characterized in binary mixed cultures [26].

For $S$. aureus, mixed culture cultivations did not affect growth of single species. Interestingly, other authors reported inhibition of growth in similar mixed cultures $[10,46]$, possibly caused by interspecies competition for glucose and glutamine [10] as well as through action of antistaphylococcal pyocyanine or pseudomonas quinoline signals (PQS) produced by $P$. aeruginosa [46-48]. Although the ratio between species used to initiate mixed culture experiments was similar to the study of Riedele et al. [10], in this study, growth characteristics of $S$. aureus 
were comparable between mixed and pure cultures. This is probably attributed to more favorable growth conditions for the Gram-positive bacteria in mixed culture at reduced starting cell concentrations of each species, e.g. due to the higher ratio of initial substrate-to-biomass [49]. However, $S$. aureus seems to be outcompeted during stationary growth phase, as cell concentrations decreased in mixed culture towards the end of cultivation. This may be explained by action of inhibitory and lytic active substances produced by the competing species. Especially, $P$. aeruginosa is known to produce antistaphylococcal virulence factors, either bactericidal active, e.g. phenazine pyocyanine [50,51], or bacteriolytic active, e.g. LasA protease [52]. This hypothesis is further supported by results obtained in a proteomic study published recently by Kluge et al., where induction of phenazine synthesis of $P$. aeruginosa was suggested due to increased expression levels of PhzS, PhzD and PhzG2 in a similar mixed culture [46]. Additionally, the authors found for S. aureus an increased expression level of an alkyl hydroperoxide reductase, which typically evokes resistance against oxidative stress. Despite of antistaphylococcal action of $P$. aeruginosa in mixed culture, it is likely, that virulence factors of B. cepacia also contribute to lysis of $S$. aureus, e.g. peptidoglycan hydrolases [53]. This interaction, however, still needs to be demonstrated. Cell concentrations of B. cepacia in pure and mixed culture determined by qTRFLP might, however, be underestimated, in particular at time point of inoculation. Although cell concentrations were adjusted (see Methods), the determined values were up to one-log unit below concentrations measured for $P$. aeruginosa and $S$. aureus. In contrast, flow cytometry suggested for B. cepaciaa cell concentration in mixed culture at time point of inoculation to as high as adjusted (see Methods). Detected relative frequencies revealed a ratio between starting cell concentrations of species of about 1:1:1 (Figure 7(C)).

In general, viability of species shifted over the cultivation period. Experimental data indicates that the loss of viability in pure culture during stationary phase, particularly for $P$. aeruginosa and $S$. aureus, is a consequence of the depletion of the main substrates glucose, glutamine and glutamate within the first $12 \mathrm{~h}$ of cultivation. Moreover, gluconate and 2-KDG were also depleted within this time period, which are intermediates produced via extracellular glucose oxidation by $P$. aeruginosa and B. cepacia $[54,55]$. With depletion of nutrients the metabolic activity decreases and active transports are impaired, which eventually leads to permeabilization of cytoplasmic membranes [34]. In contrast, viability of $B$. cepacia in pure culture remained relatively constant throughout the entire cultivation period, although the main substrates and metabolites were also depleted within the first $12 \mathrm{~h}$ of cultivation. Interestingly, in this phase, growth of B. cepacia was still detected by increasing cell concentrations by qT-RFLP analysis. The latter suggests an uptake of other substrates available for growth in the culture medium, e.g. amino acids. Reduced viability levels during exponential growth phase, as observed most prominently for $S$. aureus, may be caused by PI false positive stained cells. This can probably be attributed to the entry of PI due to short-term perforation of cell walls during cell division and cell wall synthesis [13,56]. Additionally, for S. aureus, aggregates of viable and dead cells might also increase total number of damaged bacteria due to clumping during growth [57].

Mixed culture cultivation impaired viability of B. cepacia and $S$. aureus, but did not affect viability of $P$. aeruginosa. For B. cepacia, viability in mixed cultures was reduced slightly compared to pure cultures from $12 \mathrm{~h}$ to $32 \mathrm{~h}$. This may be caused by action of inhibitory pyocins produced by $P$. aeruginosa, as discussed above. For $S$. aureus, clear differences in the time course of viability in mixed and pure cultures were found. In mixed culture, viability decreased earlier and initially at a faster rate than in pure culture. This can most probably be explained by antagonistic interactions from Gram-negative bacteria towards $S$. aureus, most likely from $P$. aeruginosa due to dominance with regard to cell concentrations in mixed culture. Antistaphylococcal action can be transmitted by expressed virulence factors, e.g. pyocyanine or LasA protease, as discussed above. However, earlier reduction in viability of S. aureus in mixed culture may be additionally caused by other virulence factors, e.g. peptidoglycan hydrolases produced by B. cepacia [53]. Moreover, differences in dynamics of damaged and dead cells of $S$. aureus between pure and mixed culture clearly suggest the presence of various damaging processes in mixed culture, differing at least in time of action, which finally lead to a loss of membrane integrity. In general, the detection of damaged $S$. aureus cells might reflect a slower damaging process of membranes than for B. cepacia and P. aeruginosa, which is most probably due to differences in cell wall structures. Interestingly, for B. cepacia and S. aureus in mixed culture, a simultaneous increase of relative frequency of dead cells and a decrease of cell concentration was observed. These results suggest co-occurrence of cell dead (loss of membrane integrity) and lysis, which would further support simultaneous action of a set of various antagonistic interspecies effects during co-cultivation, differing in mode and time of action. Despite of this, synergistic interactions between the species cannot be excluded. For instance, Riedel et al. reported in their study of increased pathogenicity of $B$. cepacia induced by $P$. aeruginosa via quorum sensing signaling [58]. However, proteome data presented in a recently published report of Kluge et al. suggested no synergistic interspecies effects between the three species of interest in a similar mixed culture [46]. 
In the presented study, iron availability in the culture medium was not analyzed, although it might have a certain impact on growth and viability of single species in mixed culture. Iron limitation in medium in mixed culture will probably evoke interspecies effects for competition for remaining iron. Moreover, the expression of virulence factors might be regulated based on iron occurrence, as reported for $P$. aeruginosa for a large number of factors $[59,60]$. The impact of iron availability on growth and viability in the mixed culture remains to be clarified in further studies.

Overall, $P$. aeruginosa clearly dominated the mixed culture after $6 \mathrm{~h}$ of cultivation, with regard to the obtained cell concentrations. This emphasizes the predominance of $P$. aeruginosa over $B$. cepacia and $S$. aureus in the mixed culture under the chosen cultivation conditions, particularly due to very efficient substrate consumption of $P$. aeruginosa. Additionally, obtained growth and viability results suggest predominance of $P$. aeruginosa by induced antagonistic interspecies effects against $B$. cepacia and $S$. aureus. Interestingly, in patients with CF disease, $P$. aeruginosa is also often found to dominate late-term lung infections. This suggests that $P$. aeruginosa is dominant over B. cepacia and $S$. aureus in mixed community under a variety of growth conditions.

\section{Conclusion}

A three-species mixed culture comprising $P$. aeruginosa, $B$. cepacia and $S$. aureus was characterized using a combination of analytical assays for monitoring species-specific cell concentrations and viabilities as well as determination of substrates and extracellular metabolites in the culture medium. The approach allowed for a comprehensive description of mixed culture dynamics of bacteria relevant to lung infections of CF patients, and enabled the identification of interspecies effects. In addition, the characterization of species-specific viability by flow cytometry provided insights into dynamics of cell damage in mixed cultures.

\section{Competing interests}

The authors declare that they have no competing interests.

\section{Authors' contributions}

MR designed the study, did the laboratory work, analyzed the data and wrote the manuscript. MA participated in laboratory work and data analysis. UR supervised the study and helped to draft the manuscript. All authors read and approved the final manuscript.

\section{Acknowledgments}

The authors cordially thank Corina Siewert for excellent technical assistance.

\section{Author details}

${ }^{1}$ Chair of Bioprocess Engineering, Otto von Guericke University, Magdeburg, Germany. ${ }^{2}$ Bioprocess Engineering, Max Planck Institute for Dynamics of Complex Technical Systems, Magdeburg, Germany.

Received: 30 April 2013 Accepted: 25 February 2014

Published: 7 March 2014

\section{References}

1. Hullar MAJ, Kaplan LA, Stahl DA: Recurring seasonal dynamics of microbial communities in stream habitats. Appl Environ Microbiol 2006, 72(1):713-722

2. Katsivela E, Moore E, Maroukli D, Strömpl C, Pieper D, Kalogerakis N: Bacterial community dynamics during in-situ bioremediation of petroleum waste sludge in landfarming sites. Biodegradation 2005, 16(2):169-180.

3. Kleinsteuber S, Schleinitz KM, Breitfeld J, Harms H, Richnow HH, Vogt C: Molecular characterization of bacterial communities mineralizing benzene under sulfate-reducing conditions. FEMS Microbiol Ecol 2008, 66(1):143-157.

4. Liu WT, Marsh TL, Cheng H, Forney LJ: Characterization of microbial diversity by determining terminal restriction fragment length polymorphisms of genes encoding 16S rRNA. App/ Environ Microbiol 1997, 63(11):4516-4522.

5. Rogers GB, Hart CA, Mason JR, Hughes M, Walshaw MJ, Bruce KD: Bacterial diversity in cases of lung infection in cystic fibrosis patients: $16 \mathrm{~S}$ ribosomal DNA (rDNA) length heterogeneity PCR and 16S rDNA terminal restriction fragment length polymorphism profiling. J Clin Microbiol 2003, 41(8):3548-3558.

6. Thies FL, König W, König B: Rapid characterization of the normal and disturbed vaginal microbiota by application of 16S rRNA gene terminal RFLP fingerprinting. J Med Microbio/ 2007, 56(6):755-761.

7. Trotha R, Reichl U, Thies FL, Sperling D, König W, König B: Adaption of a fragment analysis technique to an automated high-throughput multicapillary electrophoresis device for the precise qualitative and quantitative characterization of microbial communities. Electrophoresis 2002, 23(7-8):1070-1079.

8. Schmidt JK, König B, Reichl U: Characterization of a three bacteria mixed culture in a chemostat: evaluation and application of a quantitative terminal-restriction fragment length polymorphism (T-RFLP) analysis for absolute and species specific cell enumeration. Biotechnol Bioeng 2007, 96(4):738-756.

9. Schmidt JK, Riedele C, Regestein L, Rausenberger J, Reichl U: A novel concept combining experimental and mathematical analysis for the identification of unknown interspecies effects in a mixed culture. Biotechnol Bioeng 2011, 108(8):1900-1911.

10. Riedele C, Reichl U: Interspecies effects in a ceftazidime-treated mixed culture of Pseudomonas aeruginosa, Burkholderia cepacia and Staphylococcus aureus: analysis at the single-species level. J Antimicrob Chemother 2011, 66(1):138-145.

11. Rogers GB, Stressmann FA, Koller G, Daniels T, Carroll MP, Bruce KD: Assessing the diagnostic importance of nonviable bacterial cells in respiratory infections. Diagn Microbiol Infect Dis 2008, 62(2):133-141.

12. Nocker A, Sossa-Fernandez P, Burr MD, Camper AK: Use of propidium monoazide for live/dead distinction in microbial ecology. Appl Environ Microbiol 2007, 73(16):5111-5117.

13. Sträuber $H$, Müller S: Viability states of bacteria-specific mechanisms of selected probes. Cytometry A 2010, 77A(7):623-634.

14. Fittipaldi $M$, Nocker $A$, Codony F: Progress in understanding preferential detection of live cells using viability dyes in combination with DNA amplification. J Microbiol Methods 2012, 91(2):276-289.

15. Hammes F, Berney M, Egli T: Cultivation-independent assessment of bacterial viability. In High Resolution Microbial Single Cell Analytics. Edited by Müller S, Bley T. Heidelberg, Berlin: Springer; 2011:123-150 [Scheper T (Series Editor): Advances in biochemical engineering/biotechnology, volume 124.].

16. Gregori G, Citterio S, Ghiani A, Labra M, Sgorbati S, Brown S, Denis M: Resolution of viable and membrane-compromised bacteria in freshwater and marine waters based on analytical flow cytometry and nucleic acid double staining. Appl Environ Microbiol 2001, 67(10):4662-4670.

17. Alonso-Sáez L, Gasol JM, Lefort T, Hofer J, Sommaruga R: Effect of natural sunlight on bacterial activity and differential sensitivity of natural bacterioplankton groups in northwestern mediterranean coastal waters. Appl Environ Microbiol 2006, 72(9):5806-5813.

18. Berney M, Hammes F, Bosshard F, Weilenmann H-U, Egli T: Assessment and interpretation of bacterial viability by using the LIVE/DEAD BacLight Kit in combination with flow cytometry. Appl Environ Microbiol 2007, 73(10):3283-3290.

19. Bensch $G$, Rüger M, Wassermann M, Weinholz S, Reichl U, Cordes C: Flow cytometric viability assessment of lactic acid bacteria starter 
cultures produced by fluidized bed drying. Appl Microbiol Biotechnol 2014. DOI 10.1007/s00253-014-5592-z.

20. Falcioni T, Papa S, Gasol JM: Evaluating the flow-cytometric nucleic acid double-staining protocol in realistic situations of planktonic bacterial death. Appl Environ Microbiol 2008, 74(6):1767-1779.

21. Foladori P, Bruni L, Tamburini S, Ziglio G: Direct quantification of bacterial biomass in influent, effluent and activated sludge of wastewater treatment plants by using flow cytometry. Water Res 2010, 44(13):3807-3818.

22. Johnson DR, Czechowska K, Chèvre N, Van Der Meer JR: Toxicity of triclosan, penconazole and metalaxyl on Caulobacter crescentus and a freshwater microbial community as assessed by flow cytometry. Environ Microbiol 2009, 11(7):1682-1691.

23. Ziglio G, Andreottola G, Barbesti S, Boschetti G, Bruni L, Foladori P, Villa R: Assessment of activated sludge viability with flow cytometry. Water Res 2002, 36(2):460-468.

24. Shapiro HM: Practical Flow Cytometry. 4th edition. New York: Wiley-Liss; 2003:306-307.

25. Zipper $\mathrm{H}$, Brunner $\mathrm{H}$, Bernhagen J, Vitzthum F: Investigations on DNA intercalation and surface binding by SYBR Green I, its structure determination and methodological implications. Nucleic Acids Res 2004, 32(12):e103-e103.

26. Rüger M, Bensch G, Tüngler R, Reichl U: A flow cytometric method for viability assessment of Staphylococcus aureus and Burkholderia cepacia in mixed culture. Cytometry A 2012, 81A(12):1055-1066.

27. Müller S, Nebe-von-Caron G: Functional single-cell analyses: flow cytometry and cell sorting of microbial populations and communities. FEMS Microbiol Rev 2010, 34(4):554-587.

28. Riedele C, Reichl U: Time-kill studies with a ceftazidime-treated mixed culture consisting of Pseudomonas aeruginosa, Burkholderia cepacia and Staphylococcus aureus. Eng Life Sci 2012, 12(2):188-197.

29. Holm C, Jespersen L: A flow-cytometric gram-staining technique for milk-associated bacteria. Appl Environ Microbiol 2003, 69(5):2857-2863.

30. Gensberger ET, Sessitsch A, Kostić T: Propidium monoazide-quantitative polymerase chain reaction for viable Escherichia coli and Pseudomonas aeruginosa detection from abundant background microflora. Anal Biochem 2013, 441(1):69-72.

31. Løvdal T, Hovda MB, Björkblom B, Møller SG: Propidium monoazide combined with real-time quantitative PCR underestimates heat-killed Listeria innocua. J Microbiol Methods 2011, 85(2):164-169.

32. Pan $Y$, Breidt F: Enumeration of viable Listeria monocytogenes cells by real-time PCR with propidium monoazide and ethidium monoazide in the presence of dead cells. Appl Environ Microbiol 2007, 73(24):8028-8031.

33. Yáñez MA, Nocker A, Soria-Soria E, Múrtula R, Martínez L, Catalán V: Quantification of viable Legionella pneumophila cells using propidium monoazide combined with quantitative PCR. J Microbio/ Methods 2011 . 85(2):124-130

34. Nebe-von-Caron G, Badley RA: Viability assessment of bacteria in mixed populations using flow cytometry. J Microsc 1995, 179:55-66.

35. Barbesti S, Citterio S, Labra M, Baroni MD, Neri MG, Sgorbati S: Two and three-color fluorescence flow cytometric analysis of immunoidentified viable bacteria. Cytometry 2000, 40(3):214-218

36. Van Dilla MA, Langlois RG, Pinkel D, Yajko D, Hadley WK: Bacterial characterization by flow cytometry. Science 1983, 220(4597):620-622

37. Debray H, Decout D, Strecker G, Spik G, Montreuil J: Specificity of twelve lectins towards oligosaccharides and glycopeptides related to N-glycosylproteins. Eur J Biochem 1981, 117(1):41-51.

38. Sizemore RK, Caldwell JJ, Kendrick AS: Alternate gram-staining technique using a fluorescent lectin. Eur J Biochem 1990, 56(7):2245-2247.

39. Forsgren A, Sjöquist J: "Protein a" from S. aureus: I. Pseudo-immune reaction with human $\gamma$-globulin. J Immunol 1966, 97(6):822-827.

40. Inganäs $\mathrm{M}$, Johansson SGO, Bennich $\mathrm{HH}$ : Interaction of human polyclonal $\lg E$ and $\lg G$ from different species with protein a from Staphylococcus aureus: demonstration of protein-a-reactive sites located in the Fab2 fragment of human IgG. Scand J Immunol 1980, 12(1):23-31.

41. Ljungberg UK, Jansson B, Niss U, Nilsson R, Sandberg BEB, Nilsson B: The interaction between different domains of staphylococcal protein a and human polyclonal $\lg G$, $\lg A$, $\lg M$ and $F\left(a b^{\prime}\right) 2$ : separation of affinity from specificity. Mol Immunol 1993, 30(14):1279-1285.

42. Hughes EE, Gilleland HE Jr, Matthews-Greer JM: Analysis by flow cytometry of surface-exposed epitopes of outer membrane protein $\mathrm{F}$ of Pseudomonas aeruginosa. Can J Microbiol 1996, 42(8):859-862.
43. Nakayama K, Takashima K, Ishihara H, Shinomiya T, Kageyama M, Kanaya S, Ohnishi M, Murata T, Mori H, Hayashi T: The R-type pyocin of Pseudomonas aeruginosa is related to $\mathrm{P} 2$ phage, and the F-type is related to lambda phage. Mol Microbiol 2000, 38(2):213-231.

44. Waite RD, Curtis MA: Pseudomonas aeruginosa PAO1 pyocin production affects population dynamics within mixed-culture biofilms. J Bacteriol 2009, 191(4):1349-1354.

45. Bakkal S, Robinson SM, Ordonez CL, Waltz DA, Riley MA: Role of bacteriocins in mediating interactions of bacterial isolates taken from cystic fibrosis patients. Microbiology 2010, 156(7):2058-2067.

46. Kluge S, Hoffmann M, Benndorf D, Rapp E, Reichl U: Proteomic tracking and analysis of a bacterial mixed culture. Proteomics 2012, 12(12):1893-1901.

47. Machan ZA, Taylor GW, Pitt TL, Cole PJ, Wilson R: 2-Heptyl-4hydroxyquinoline $\mathrm{N}$-oxide, an antistaphylococcal agent produced by Pseudomonas aeruginosa. J Antimicrob Chemother 1992, 30(5):615-623.

48. Voggu L, Schlag S, Biswas R, Rosenstein R, Rausch C, Götz F: Microevolution of cytochrome bd oxidase in staphylococci and its implication in resistance to respiratory toxins released by pseudomonas. J Bacterio/ 2006, 188(23):8079-8086.

49. Kovárová-Kovar K, Egli T: Growth kinetics of suspended microbial cells: from single-substrate-controlled growth to mixed-substrate kinetics. Microbiol Mol Biol Rev 1998, 62(3):646-666.

50. Baron SS, Rowe JJ: Antibiotic action of pyocyanin. Antimicrob Agents Chemother 1981, 20(6):814-820.

51. Biswas L, Biswas R, Schlag M, Bertram R, Götz F: Small-colony variant selection as a survival strategy for Staphylococcus aureus in the presence of Pseudomonas aeruginosa. Appl Environ Microbiol 2009, 75(21):6910-6912.

52. Kessler E, Safrin M, Olson JC, Ohman DE: Secreted LasA of Pseudomonas aeruginosa is a staphylolytic protease. J Bio/ Chem 1993, 268(10):7503-7508.

53. Allan ND, Kooi C, Sokol PA, Beveridge TJ: Putative virulence factors are released in association with membrane vesicles from Burkholderia cepacia. Can J Microbiol 2003, 49(10):613-624.

54. Lessie TG, Phibbs PV: Alternative pathways of carbohydrate utilization in pseudomonads. Annu Rev Microbiol 1984, 38(1):359-388.

55. Roberts BK, Midgley M, Dawes EA: The metabolism of 2-oxogluconate by Pseudomonas aeruginosa. J Gen Microbio/ 1973, 78(2):319-329.

56. David F, Berger A, Hansch R, Rohde M, Franco-Lara E: Single cell analysis applied to antibody fragment production with Bacillus megaterium: development of advanced physiology and bioprocess state estimation tools. Microb Cell Fact 2011, 10(1):23.

57. Shapiro HM: Multiparameter flow cytometry of bacteria: Implications for diagnostics and therapeutics. Cytometry 2001, 43(3):223-226.

58. Riedel K, Hentzer M, Geisenberger O, Huber B, Steidle A, Wu H, Høiby N, Givskov M, Molin S, Eberl L: N-Acylhomoserine-lactone-mediated communication between Pseudomonas aeruginosa and Burkholderia cepacia in mixed biofilms. Microbiology 2001, 147(12):3249-3262.

59. Kim E-J, Wang W, Deckwer W-D, Zeng A-P: Expression of the quorum-sensing regulatory protein LasR is strongly affected by iron and oxygen concentrations in cultures of Pseudomonas aeruginosa irrespective of cell density. Microbiology 2005, 151(4):1127-1138.

60. Ochsner UA, Wilderman PJ, Vasil Al, Vasil ML: GeneChip ${ }^{\circledR}$ expression analysis of the iron starvation response in Pseudomonas aeruginosa: identification of novel pyoverdine biosynthesis genes. Mol Microbio/ 2002, 45(5):1277-1287

doi:10.1186/1471-2180-14-56

Cite this article as: Rüger et al:: Species-specific viability analysis of

Pseudomonas aeruginosa, Burkholderia cepacia and Staphylococcus aureus in mixed culture by flow cytometry. BMC Microbiology 2014 14:56. 